\title{
Impact of Positive Peri-Stent Vascular Remodeling After Sirolimus-Eluting and Paclitaxel-Eluting Stent Implantation on 5-Year Clinical Outcomes
}

\section{- Intravascular Ultrasound Analysis From the Poststent Optimal Stent Expansion Trial Multicenter Randomized Trial -}

\author{
Ki-Woon Kang, MD; Young-Guk Ko, MD; Dong-Ho Shin, MD, PhD; Jung-Sun Kim, MD, PhD; \\ Byeong-Keuk Kim, MD, PhD; Donghoon Choi, MD, PhD; Myeong-Ki Hong, MD, PhD; \\ Woong Chol Kang, MD, PhD; Taehoon Ahn, MD, PhD; Dong Woon Jeon, MD, PhD; \\ Joo-Young Yang, MD, PhD; Yangsoo Jang, $\mathrm{MD}, \mathrm{PhD}$
}

\begin{abstract}
Background: Positive peri-stent vascular remodeling (PPVR) after drug-eluting stent (DES) implantation is an important mechanism of late-acquired stent malapposition (LASM).

Methods and Results: A total of 226 patients (sirolimus-eluting stent [SES], $n=105$; paclitaxel-eluting stent [PES], $\mathrm{n}=121$ ) from the Poststent Optimal Stent Expansion Trial who underwent a post-intervention and 9-month follow-up intravascular ultrasound were followed clinically for 5 years. PPVR was arbitrarily defined as a $>10 \%$ increase in the external elastic membrane volume index at follow-up. PPVR and LASM occurred more frequently with SESs than with PESs. The 5-year rate of major adverse cardiac events was lower with SES than with PES (10.7\% vs. $23.2 \%$, $\mathrm{P}=0.002)$. The late and very late stent thrombosis (ST) rate was similar between the $2 \mathrm{DES}$ types, but it was higher in patients with PPVR than in those without PPVR $(8.8 \%$ vs. $1.3 \%, \mathrm{P}=0.009)$ regardless of the DES type. Early discontinuation (<1 year) of dual antiplatelet therapy (DAPT; hazard ratio [HR], 24.14; 95\% confidence interval [CI]: 4.90-118.87; $\mathrm{P}<0.001)$, PPVR (HR, 14.94; 95\%Cl: 1.85-120.46; $\mathrm{P}=0.011)$, LASM (HR, 8.01; 95\%Cl: 1.93-33.16; $\mathrm{P}=0.004)$, and stent length $(\mathrm{HR}, 1.14 ; 95 \% \mathrm{Cl}: 0.98-1.32$ per $\mathrm{mm} ; \mathrm{P}=0.078)$ were associated with increased risk of late and very late ST.
\end{abstract}

Conclusions: PPVR and LASM development after DES implantation, along with early discontinuation of DAPT and longer stent length, are important risk factors of late and very late ST. (Circ J 2012; 76: 1102-1108)

Key Words: Coronary artery disease; Drug-eluting stent; Late and very late stent thrombosis; Vascular remodeling

W hen compared to the bare metal stent (BMS), the drug-eluting stent (DES) has significantly reduced restenosis by inhibiting neointimal hyperplasia. ${ }^{1-3}$ Infrequent late or very late stent thrombosis (ST), however, has emerged as a major concern after implantation of a DES.,45 Although the precise mechanism of ST is not fully understood, delayed endothelial healing in response to a DES, occurrence of late acquired stent malapposition (LASM), and inflammatory reaction related to the DES may be generally associated with the development of late or very late ST. Previous studies have suggested positive peri-stent vascular remodeling (PPVR) as an important mechanism of LASM. ${ }^{6,7}$ Recently, LASM has been reported to occur more frequently in patients treated with DES than those treated with BMS. ${ }^{6,8}$ Whereas neointimal hyperplasia has been the main focus of interest after implantation of stents, there have been little data on the PPVR associated with LASM after DES implantation. Whether differences in the tendency to develop PPVR and LASM after stent implantation exist among various types of DESs is not well known. In addition, there has been a paucity of data on the long-term

Received November 11, 2011; revised manuscript received January 1, 2012; accepted January 11, 2012; released online March 1, 2012 Time for primary review: 33 days

Division of Cardiology, Eulji University Hospital, Daejeon (K.-W.K.); Division of Cardiology, Severance Cardiovascular Hospital, Yonsei University College of Medicine, Seoul (Y.-G.K., D.-H.S., J.-S.K., B.-K.K., D.C., M.-K.H., Y.J.); Division of Cardiology, Gil Heart Center, Gachon Medical School, Incheon (W.C.K., T.A.); and Division of Cardiology, NHIC Ilsan Hospital, Koyang (D.W.J., J.-Y.Y.), Korea

The first two authors contributed equally (K.-W.K., Y.-G.K.).

Mailing address: Yangsoo Jang, MD, PhD, Division of Cardiology, Severance Cardiovascular Center, and Severance Biomedical Science Institute, Yonsei University College of Medicine, 250 Seongsanno, Seodaemun-gu, Seoul 120-752, Korea. E-mail: jangys1212@ yuhs.ac

ISSN-1346-9843 doi:10.1253/circj.CJ-11-1313

All rights are reserved to the Japanese Circulation Society. For permissions, please e-mail: cj@j-circ.or.jp 


\begin{tabular}{|c|c|c|c|c|c|c|}
\hline & \multicolumn{3}{|c|}{ Total patients } & \multicolumn{3}{|c|}{ Analyzed patients } \\
\hline & $\begin{array}{c}\text { SES } \\
(n=152)\end{array}$ & $\begin{array}{c}\text { PES } \\
(n=149)\end{array}$ & $P$ value & $\begin{array}{c}\text { SES } \\
(n=105)\end{array}$ & $\begin{array}{c}\text { PES } \\
(n=121)\end{array}$ & $P$ value \\
\hline Age (years) & $61 \pm 9$ & $62 \pm 9$ & 0.129 & $60 \pm 9$ & $62 \pm 8$ & 0.170 \\
\hline Male gender & $43(28.2)$ & $58(38.9)$ & 0.190 & $36(34.3)$ & $53(43.8)$ & 0.173 \\
\hline Diabetes mellitus & 41 (26.9) & 48 (32.2) & 0.650 & $36(34.3)$ & 42 (34.7) & 0.947 \\
\hline Hypertension & 78 (51.3) & $85(57.1)$ & 0.832 & $72(68.6)$ & $81(66.9)$ & 0.887 \\
\hline Hypercholesterolemia & $35(23.0)$ & $38(25.5)$ & 0.794 & $25(31.4)$ & $33(27.2)$ & 0.552 \\
\hline Current smoker & $42(27.6)$ & $46(30.8)$ & 0.724 & 35 (33.3) & $40(33.1)$ & 0.965 \\
\hline \multicolumn{7}{|l|}{ Clinical presentation } \\
\hline Stable angina & 78 (51.3) & $74(49.6)$ & 0.516 & $50(47.6)$ & $71(58.7)$ & 0.109 \\
\hline Unstable angina & $74(48.6)$ & 75 (41.3) & 0.613 & $55(52.4)$ & $50(41.3)$ & 0.109 \\
\hline LVEF $<40 \%$ & $3(1.9)$ & $2(1.3)$ & 0.796 & $1(1.0)$ & $1(0.8)$ & 0.920 \\
\hline Prior PCl & $7(4.6)$ & $9(6.1)$ & 0.435 & $1(1.0)$ & $1(0.8)$ & 0.920 \\
\hline
\end{tabular}

Data given as $\mathrm{n}(\%)$ or mean \pm SD. All comparisons between groups performed using Student's t-test or chi-square test. SES, sirolimus-eluting stent; PES, paclitaxel-eluting stent; LVEF, left ventricular ejection fraction; $\mathrm{PCI}$, percutaneous coronary intervention.

clinical impact of PPVR after DES implantation. Therefore, the purpose of this study was to compare the prevalence of PPVR and LASM between paclitaxel-eluting stents (PESs; Taxus; Boston Scientific, Natick, MA, USA) and sirolimus-eluting stents (SESs; Cypher; Cordis, Miami Lakes, FL, USA) and to investigate the long-term impact of PPVR on clinical outcomes after implantation of first-generation DES.

\section{Methods}

The Poststent Optimal Stent Expansion Trial was a prospective, open-label, multicenter, $2 \times 2$ factorial, randomized study comparing the efficacy of DES between PES and SES, and the efficacy of post-stent balloon dilation between non-compliant and semicompliant balloon for optimal stent expansion in patients with de novo native coronary lesions., ${ }^{9,10}$ The primary endpoint of this trial was frequency of optimal stent expansion after dilatation, as measured on intravascular ultrasound (IVUS), using an adjunctive non-compliant balloon (Quantum, Boston Scientific) compared with a semicompliant balloon (Maverick, Boston Scientific), and the secondary endpoint was rate of optimal stent expansion, compared between the PES (Taxus; Boston Scientific) and SES (Cypher; Cordis) arms. From April 2005 through August 2006, a total of 301 patients were enrolled in 3 percutaneous coronary intervention centers. This trial was approved by the Institutional Review Board of each participating center and patient informed consent was obtained before the procedure. Patients were eligible for the trial if they had a diagnosis of stable or unstable angina pectoris, with a de novo target lesion of a native coronary artery with a reference vessel diameter of $2.5-3.5 \mathrm{~mm}$ and lesion length of $\leq 28 \mathrm{~mm}$ that could be covered by a single stent. Patients with acute myocardial infarction within the previous 7 days, allergy to antiplatelet agents or contrast dye, or renal insufficiency with a serum creatinine level $>2.0 \mathrm{mg} / \mathrm{dl}$ were excluded. In addition, complex lesions, such as lesions containing a thrombus or heavy calcification, lesions involving a bifurcation requiring a kissing balloon technique, an unprotected left main coronary artery, or chronic total occlusion were also excluded. Of the 301 patients (152 SES and 149 PES) originally enrolled in the study, a total of 226 patients (105 SES and 121 PES) who completed post-intervention, follow-up IVUS and clinical 5-year follow-up were analyzed in this study.
All patients received loading doses of $200 \mathrm{mg}$ aspirin and 300-600 mg clopidogrel prior to coronary intervention, followed by daily doses of $100 \mathrm{mg}$ aspirin and $75 \mathrm{mg}$ clopidogrel, if they were not already on a maintenance dose for at least 5 days. Unfractionated heparin (100 Units/kg) was given to maintain an activated clotting time of $>250$ s during the procedure. Balloon pre-dilation was mandatory. Stent implantation was performed using current conventional techniques and interventional strategies. If optimal stent expansion was not achieved after stent implantation, post-implantation dilation was performed according to the study protocol, as described previously., ${ }^{9,10}$ Optimal stent expansion was defined according to the IVUS criteria of the Multicenter Ultrasound Stenting in Coronaries study ${ }^{11}$ as a minimum stent area $\geq 90 \%$ of the average reference lumen area immediately after stent implantation. If the minimal lumen cross-sectional area was $>9 \mathrm{~mm}^{2}$, optimal stent expansion was defined as a minimum stent area $\geq 80 \%$ of the average reference cross-sectional area.

IVUS was performed after intervention and at the 9-month follow-up (after $0.2 \mathrm{mg}$ i.c. nitroglycerin), using a commercially available IVUS system (Galaxy; Boston Scientific) with a 40-MHz mechanically rotating IVUS catheter and automatic motorized $0.5-\mathrm{mm} / \mathrm{s}$ pullback device. Quantitative and qualitative analysis was performed using planimetry software (EchoPlaque; Indec Systems, Santa Clara, CA, USA) by 2 experienced analysts blinded to clinical and procedural data according to the criteria of the clinical expert consensus document on IVUS. ${ }^{12}$ Volumetric analysis at the stented segment included external elastic membrane, lumen, and stent volume data. The neointima volume was calculated as the stent minus lumen volume, and the number and percent neointima volume obstruction was calculated using the neointima volume divided by the stent volume. Volume indices were obtained by dividing volumes by the stent length $\left(\mathrm{mm}^{3} / \mathrm{mm}\right)$. PPVR was arbitrarily defined as a $>10 \%$ increase in external elastic membrane volume index from the post-intervention assessment to the follow-up period. Stent malapposition was defined as a separation of at least 1 stent strut from the intimal surface of the arterial wall that did not overlap a side branch, with evidence of blood flow (speckling) behind the strut. Stent malapposition was classified into the following 3 categories on the basis of serial assessment: (1) resolved stent malapposition, present after the procedure but no longer present at follow-up; 


\begin{tabular}{|c|c|c|c|c|c|c|}
\hline & \multicolumn{3}{|c|}{ Total patients } & \multicolumn{3}{|c|}{ Analyzed patients } \\
\hline & $\begin{array}{c}\text { SES } \\
(n=152)\end{array}$ & $\begin{array}{c}\text { PES } \\
(n=149)\end{array}$ & $P$ value & $\begin{array}{c}\text { SES } \\
(n=105)\end{array}$ & $\begin{array}{c}\text { PES } \\
(n=121)\end{array}$ & $P$ value \\
\hline Target lesion & & & 0.686 & & & 0.711 \\
\hline LAD & $77(50.6)$ & $82(55.0)$ & & $69(65.7)$ & $75(62.0)$ & \\
\hline LCX & $33(21.7)$ & $25(16.7)$ & & $14(13.3)$ & $15(12.4)$ & \\
\hline RCA & $42(27.6)$ & $42(28.1)$ & & $22(21.0)$ & $31(25.6)$ & \\
\hline Lesion type B2/C & $86(56.5)$ & $98(65.7)$ & 0.649 & $74(70.5)$ & $91(75.2)$ & 0.455 \\
\hline Lesion length (mm) & $20 \pm 4$ & $21 \pm 5$ & 0.437 & $20 \pm 6$ & $21 \pm 6$ & 0.948 \\
\hline \multicolumn{7}{|l|}{ Before intervention } \\
\hline $\mathrm{RD}(\mathrm{mm})$ & $3.0 \pm 0.4$ & $3.0 \pm 0.4$ & 0.433 & $3.1 \pm 0.4$ & $3.0 \pm 0.4$ & 0.356 \\
\hline MLD (mm) & $0.9 \pm 0.4$ & $1.0 \pm 0.4$ & 0.236 & $0.9 \pm 0.4$ & $0.9 \pm 0.4$ & 0.863 \\
\hline DS (\%) & $67 \pm 19$ & $69 \pm 11$ & 0.537 & $67 \pm 15$ & $68 \pm 14$ & 0.645 \\
\hline Mean stent diameter (mm) & $3.2 \pm 0.3$ & $3.2 \pm 0.2$ & 0.686 & $3.2 \pm 0.2$ & $3.2 \pm 0.3$ & 0.324 \\
\hline Mean stent length (mm) & $24 \pm 5$ & $24 \pm 5$ & 0.419 & $24 \pm 5$ & $24 \pm 5$ & 0.385 \\
\hline Post-stent dilatation & $131(86.1)$ & $118(79.1)$ & 0.121 & 97 (92.3) & $101(83.4)$ & 0.193 \\
\hline Optimal stent expansion & $127(83.5)$ & $113(75.8)$ & 0.317 & $93(88.6)$ & $97(80.1)$ & 0.501 \\
\hline
\end{tabular}

Data given as $\mathrm{n}(\%)$ or mean $\pm \mathrm{SD}$. All comparisons between groups performed with the Student's t-test or chi-square test.

PES, paclitaxel-eluting stent; SES, sirolimus-eluting stent; LAD, left anterior descending artery; LCX, left circumflex artery; RCA, right coronary artery; RD, reference diameter; MLD, minimums length diameter; DS, diameter stenosis.

\begin{tabular}{|c|c|c|c|}
\hline & SES $(n=105)$ & PES (n=121) & $P$ value \\
\hline \multicolumn{4}{|l|}{ After intervention } \\
\hline Vessel volume $\left(\mathrm{mm}^{3}\right)$ & $484.7 \pm 146.5$ & $481.9 \pm 136.1$ & 0.883 \\
\hline Lumen volume $\left(\mathrm{mm}^{3}\right)$ & $270.1 \pm 74.1$ & $277.8 \pm 74.1$ & 0.489 \\
\hline $\mathrm{P} \& \mathrm{M}$ volume $\left(\mathrm{mm}^{3}\right)$ & $214.6 \pm 111.2$ & $204.1 \pm 99.9$ & 0.483 \\
\hline Vessel VI (mm³/mm) & $20.4 \pm 4.9$ & $19.9 \pm 5.7$ & 0.436 \\
\hline Lumen VI (mm³/mm) & $11.4 \pm 3.1$ & $11.5 \pm 3.4$ & 0.882 \\
\hline $\mathrm{P} \& \mathrm{M}$ VI $\left(\mathrm{mm}^{3} / \mathrm{mm}\right)$ & $9.0 \pm 3.9$ & $8.4 \pm 3.9$ & 0.343 \\
\hline \multicolumn{4}{|l|}{ 9-month follow-up } \\
\hline Vessel volume $\left(\mathrm{mm}^{3}\right)$ & $535.7 \pm 158.1$ & $496.8 \pm 144.4$ & 0.184 \\
\hline Lumen volume $\left(\mathrm{mm}^{3}\right)$ & $264.9 \pm 74.6$ & $253.1 \pm 82.8$ & 0.225 \\
\hline $\mathrm{P} \& \mathrm{M}$ volume $\left(\mathrm{mm}^{3}\right)$ & $270.8 \pm 83.7$ & $243.7 \pm 93.1$ & 0.218 \\
\hline $\mathrm{NIH}$ volume $\left(\mathrm{mm}^{3}\right)$ & $5.2 \pm 8.7$ & $24.7 \pm 23.9$ & $<0.001$ \\
\hline $\mathrm{NI}$ volume obstruction (\%) & $1.9 \pm 3.5$ & $9.7 \pm 9.8$ & $<0.001$ \\
\hline Vessel VI (mm³/mm) & $22.5 \pm 5.4$ & $20.8 \pm 5.8$ & 0.028 \\
\hline Lumen VI (mm³/mm) & $11.3 \pm 3.4$ & $10.6 \pm 3.6$ & 0.147 \\
\hline $\mathrm{P} \& \mathrm{M} \mathrm{VI}(\mathrm{mm} 3 / \mathrm{mm})$ & $11.2 \pm 3.1$ & $10.2 \pm 3.7$ & 0.055 \\
\hline $\mathrm{NIH} \mathrm{VI} \mathrm{(mm³/mm)}$ & $0.2 \pm 0.3$ & $1.0 \pm 0.9$ & $<0.001$ \\
\hline \multicolumn{4}{|l|}{ Changes during follow-up } \\
\hline$\Delta$ Vessel volume $\left(\mathrm{mm}^{3}\right)$ & $51.0 \pm 65.7$ & $14.9 \pm 44.1$ & 0.001 \\
\hline$\Delta$ Lumen volume $\left(\mathrm{mm}^{3}\right)$ & $-5.2 \pm 8.7$ & $-24.7 \pm 23.9$ & $<0.001$ \\
\hline$\Delta \mathrm{P} \& \mathrm{M}$ volume $\left(\mathrm{mm}^{3}\right)$ & $56.2 \pm 94.9$ & $39.6 \pm 104.1$ & 0.015 \\
\hline$\Delta$ Vessel $\mathrm{VI}\left(\mathrm{mm}^{3} / \mathrm{mm}\right)$ & $2.1 \pm 2.7$ & $0.9 \pm 1.7$ & $<0.001$ \\
\hline$\Delta$ Lumen VI $\left(\mathrm{mm}^{3} / \mathrm{mm}\right)$ & $-0.1 \pm 0.3$ & $-0.9 \pm 0.9$ & $<0.001$ \\
\hline$\Delta \mathrm{P} \& \mathrm{M}$ VI $\left(\mathrm{mm}^{3} / \mathrm{mm}\right)$ & $2.2 \pm 3.9$ & $1.8 \pm 4.2$ & 0.011 \\
\hline \multicolumn{4}{|l|}{ Stent malapposition } \\
\hline Resolved & $0(0)$ & $3(2.5)$ & 0.252 \\
\hline Persistent & $10(9.5)$ & $4(3.3)$ & 0.058 \\
\hline Late acquired & $21(20.0)$ & $11(9.1)$ & 0.015 \\
\hline PPVR & $41(39.0)$ & $30(24.8)$ & 0.015 \\
\hline
\end{tabular}

Data given as $n(\%)$ or mean \pm SD. All comparisons between groups performed with Student's t-test or chi-square test. SES, sirolimus-eluting stent; PES, paclitaxel-eluting stent; VI, volume index; P\&M, plaque and media; $\mathrm{NIH}$, neointimal hyperplasia; PPVR, positive peri-stent vascular remodeling. 
Table 4. Clinical Outcome at 5 Years vs. DES Type and Presence of PPVR

\begin{tabular}{lllllll} 
MACE & $9(10.7)$ & $27(23.2)$ & 0.002 & $8(12.9)$ & $28(19.4)$ & 0.208 \\
Death & $0(0)$ & $0(0)$ & 1.000 & $0(0)$ & $0(0)$ & 1.000 \\
MI & $5(5.4)$ & $7(9.8)$ & 0.776 & $6(9.4)$ & $5(3.3)$ & 0.051 \\
$\mathrm{ST}^{\dagger}$ & $3(3.4)$ & $4(3.8)$ & 0.672 & $5(8.8)$ & $2(1.3)$ & 0.010 \\
$\mathrm{TVR}^{+}$ & $5(6.1)$ & $25(22.1)$ & $<0.001$ & $6(10.1)$ & $24(16.7)$ & 0.164 \\
\hline
\end{tabular}

Data given as $n$ (\%) based on Kaplan-Meier estimates. All comparisons between groups performed with the log-rank test. ${ }^{\dagger}$ All patients had late or very late ST.

DES, drug-eluting stent; PPVR, positive peri-stent vascular remodeling; SES, sirolimus-eluting stent; PES, paclitaxeleluting stent; MACE, major adverse cardiac event; MI, myocardial infarction; ST, probable or definite stent thrombosis;

TVR, target vessel revascularization.

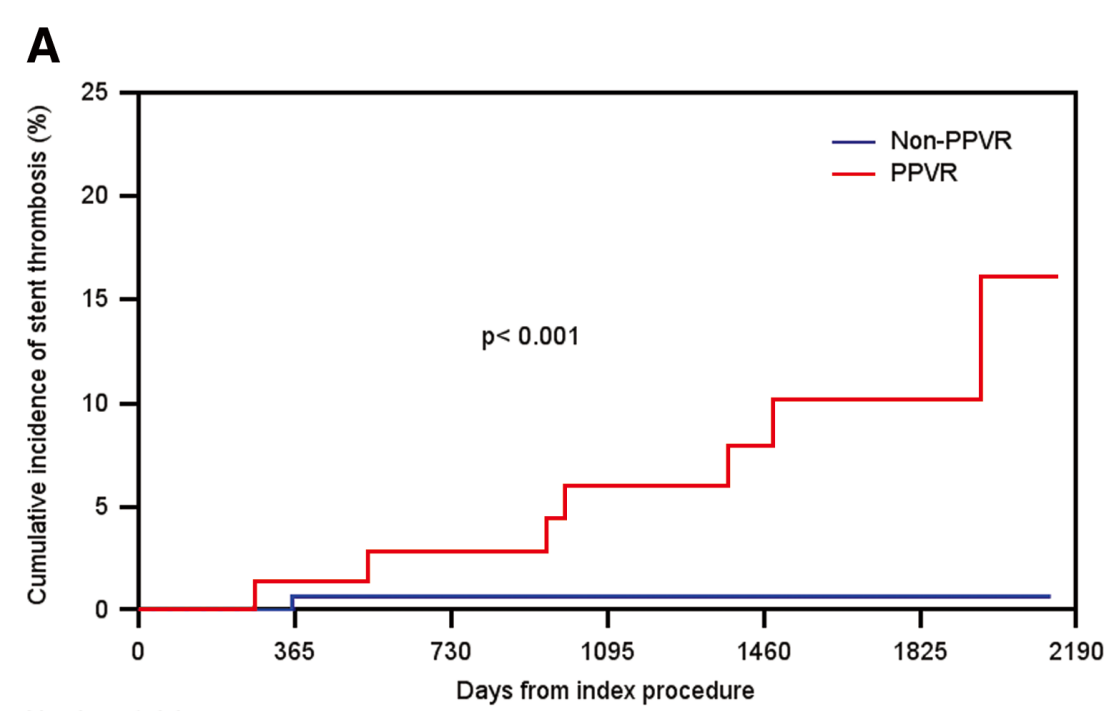

Number at risk

Group: Non-PPVR

\begin{tabular}{|c|c|c|c|c|c|c|}
\hline \multicolumn{7}{|l|}{ (10u } \\
\hline 155 & 149 & 142 & 140 & 98 & 49 & 0 \\
\hline Group: PPVR & & & & & & \\
\hline 71 & 70 & 64 & 59 & 43 & 27 & 0 \\
\hline
\end{tabular}

B

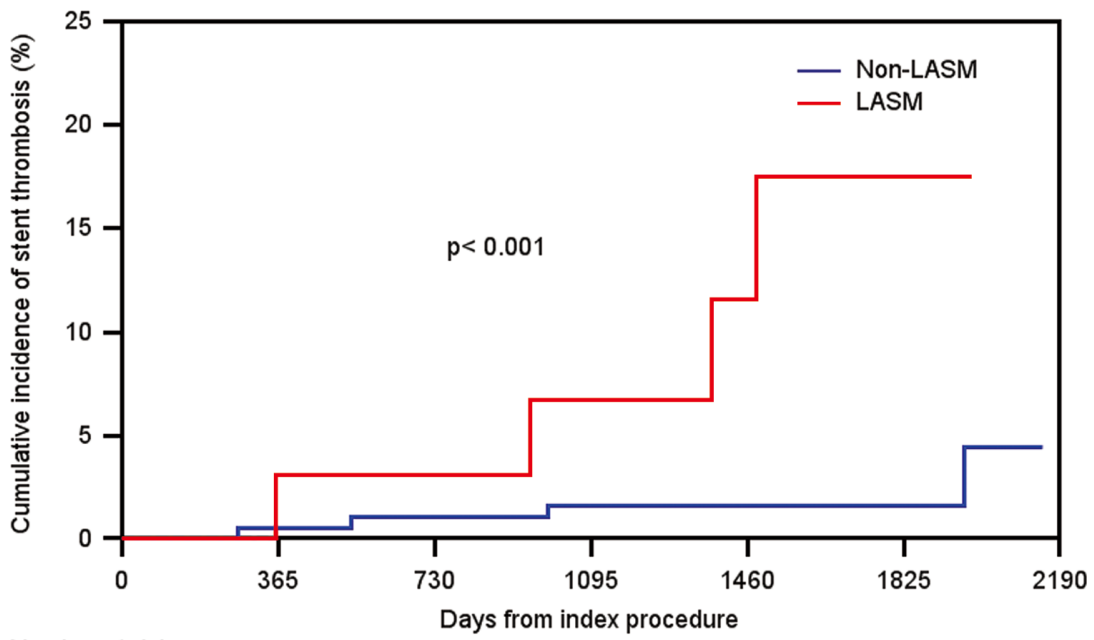

Number at risk

Days from index procedure

Figure. Cumulative incidence of probable and definite stent thrombosis

Group: Non-LASM

194
Group: LASM

188

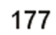

31

29

174

126

69

0

32

25

15

7 vs. (A) presence of positive peri-stent vascular remodeling (PPVR) and (B) late acquired stent malapposition (LASM) 


\begin{tabular}{|c|c|c|c|c|c|c|}
\hline \multirow[b]{3}{*}{ Clinical variables } & \multicolumn{2}{|l|}{ Univariate } & \multicolumn{2}{|c|}{ Multivariate model 1} & \multicolumn{2}{|c|}{ Multivariate model 2} \\
\hline & HR $(95 \% \mathrm{Cl})$ & $P$ value & HR $(95 \% \mathrm{Cl})$ & $P$ value & HR $(95 \% \mathrm{Cl})$ & $P$ value \\
\hline & & & & & & \\
\hline Age (years) & $0.98(0.92-1.05)$ & 0.707 & & & & \\
\hline Gender & $1.23(0.33-4.56)$ & 0.757 & & & & \\
\hline Diabetes mellitus & $1.86(0.50-6.96)$ & 0.353 & & & & \\
\hline Hypertension & $0.61(0.16-2.24)$ & 0.457 & & & & \\
\hline Dyslipidemia & $0.99(0.21-4.75)$ & 0.997 & & & & \\
\hline Unstable angina & $2.35(0.59-9.37)$ & 0.227 & & & & \\
\hline $\mathrm{DAPT}<1$ year & $24.14(4.90-118.87)$ & $<0.001$ & $15.66(3.01-80.55)$ & 0.001 & 19.17 (3.76-97.63) & $<0.001$ \\
\hline \multicolumn{7}{|l|}{ Procedural variables } \\
\hline Lesion length (mm) & $1.96(0.87-2.07)$ & 0.533 & & & & \\
\hline Stent diameter $(\mathrm{mm})$ & $3.84(0.29-49.54)$ & 0.152 & & & & \\
\hline Stent length (mm) & $1.14(0.98-1.32)$ & 0.078 & $1.08(0.94-1.24)$ & 0.233 & $1.14(1.01-1.30)$ & 0.043 \\
\hline Stent type (SES) & $1.86(0.47-7.41)$ & 0.337 & & & & \\
\hline PPVR & $14.94(1.85-120.46)$ & 0.011 & $7.47(0.84-66.20)$ & 0.072 & & \\
\hline LASM & $8.01(1.93-33.16)$ & 0.004 & & & $3.68(0.87-15.54)$ & 0.077 \\
\hline
\end{tabular}

LASM was not included in model 1. PPVR was not included in model 2.

ST, stent thrombosis; HR, hazard ratio; Cl, confidence interval; DAPT, dual antiplatelet therapy; SES, sirolimus-eluting stent; PPVR, positive peri-stent vascular remodeling; LASM, late acquired stent malapposition.

(2) persistent stent malapposition, present both after the procedure and at follow-up; and (3) LASM, not present at baseline but present at follow-up. ${ }^{13-15}$

All patients were scheduled to receive clopidogrel for 1 year and were followed in the outpatient clinic at 30 days and 3 months after the procedure and every 3 months thereafter. Patients lost to regular clinical follow-up were contacted by telephone and asked about their clinical status. A major adverse cardiac event was defined as a composite of cardiac death, myocardial infarction, and target vessel revascularization. ST was defined according to the Academic Research Consortium definitions of definite and probable ST. ${ }^{16}$ All deaths were considered cardiac deaths unless a definite non-cardiac cause could be identified. All major adverse cardiac events and ST events were adjudicated by independent clinical event committees blinded to treatment assignments.

Data are expressed as n $(\%)$ or mean \pm SD. Categorical data were compared with chi-squared statistics or Fisher's exact test, as appropriate. Continuous data were compared using Student's t-test. If the distributions were skewed, a non-parametric test was used. Cumulative incidences of clinical events were analyzed using the Kaplan-Meier method and compared between the patient groups using log-rank test. Univariate and multivariate analyses using the Cox proportional hazard regression method were performed to identify independent predictors of late or very late ST during the follow-up period of 5 years. Univariate analysis included clinical variables such as age, gender, diabetes mellitus, hypertension, dyslipidemia, unstable angina, and early (<1-year) discontinuation of dual antiplatelet therapy. Univariate analysis also included procedural variables such as stent diameter, stent length, stent type, PPVR, and LASM. Variables with $\mathrm{P}<0.15$ on univariate analysis were entered into multivariate regression analysis. Statistical analysis was performed using SPSS version 18.0 (SPSS, Chicago, IL, USA). $\mathrm{P}<0.05$ was considered statistically significant.

\section{Results}

Baseline clinical characteristics presented in Table 1. There were no significant differences in the clinical variables between the 2 groups treated with SES or PES. Lesion and procedural data did not differ between the groups (Table 2). Post-intervention and follow-up volumetric IVUS data are given in Table 3. Percent neointima volume obstruction $(1.9 \pm 3.5 \%$ vs. $9.7 \pm 9.8 \%$; $\mathrm{P}<0.001)$ and neointima volume index $\left(0.2 \pm 0.3 \mathrm{~mm}^{3} / \mathrm{mm}\right.$ vs. $\left.1.0 \pm 0.9 \mathrm{~mm}^{3} / \mathrm{mm} ; \mathrm{P}<0.001\right)$ were significantly smaller for SES than for PES. PPVR (39.0\% vs. $24.8 \%$; $\mathrm{P}=0.015)$ and LASM (20.0\% vs. $9.1 \%$; $\mathrm{P}=0.034)$ were more frequently observed in the SES-treated lesions than the PES-treated lesions. Most (93\%) of the LASMs were associated with the presence of PPVR.

The 5-year clinical outcomes are summarized in Table 4. There was a significantly lower rate of major adverse cardiac events with SES than with PES (10.7\% vs. $23.2 \%$; $\mathrm{P}=0.002)$, mainly driven by the difference in target vessel revascularization $(6.1 \%$ vs. $22.1 \%$; $\mathrm{P}<0.001)$. The rates of cardiac death, myocardial infarction, or ST, however, did not differ between the 2 DES types. Based on the 9-month follow-up IVUS, patients were divided into the PPVR $(n=71)$ or the non-PPVR $(n=155)$ groups. There was no significant difference in the baseline clinical and procedural characteristics between the PPVR and the non-PPVR patient groups, except for a higher frequency of unstable angina in the PPVR group $(67.6 \%$ vs. $36.8 \%$; $\mathrm{P}<0.001)$. Major adverse cardiac event, cardiac death, myocardial infarction, and target vessel revascularization at 5 years did not differ significantly between the 2 groups. ST, however, occurred more frequently in the PPVR group than in the non-PPVR group ( $8.8 \%$ vs. $1.3 \%$; $\mathrm{P}=0.009$; Figure $\mathbf{A})$. Similarly, the patients with LASM more frequently experienced ST than the patients without LASM (17.5\% vs. $1.6 \%$; $\mathrm{P}<0.001$; Figure B).

Cox proportional hazard regression analysis was performed to determine risk factors of ST (Table 5). On univariate analysis, early (<1-year) discontinuation of dual antiplatelet therapy, PPVR, and LASM were found to be associated with increased risk of ST. Because there was a large overlap between the PPVR patient group and the LASM patient group, 2 analysis models were used for the multivariate regression analysis. In model 1, which excluded LASM, early ( $<1$-year) discontinuation of dual antiplatelet therapy (hazard ratio [HR], 15.66; 95\% confidence interval $[\mathrm{CI}]$ : $3.01-80.55 ; \mathrm{P}=0.001$ ) was identified 
as an independent risk factor of ST. PPVR also showed a trend toward statistical significance (HR, 7.47; 95\%CI: 0.84-66.20; $\mathrm{P}=0.072$ ). In model 2, which excluded PPVR, early discontinuation ( $<1$ year) of dual antiplatelet therapy (HR, 19.17; 95\%CI: 3.76-97.63; $\mathrm{P}<0.001)$ and stent length (HR, 1.14; 95\%CI: 1.011.30 per $\mathrm{mm} ; \mathrm{P}=0.043$ ) were independent risk factors of $\mathrm{ST}$. LASM showed a trend toward statistical significance (HR, 3.68; 95\%CI: 0.87-15.54; $\mathrm{P}=0.077)$.

\section{Discussion}

The major findings of this study are the following: (1) PPVR and LASM were more frequently observed with SES than with PES; (2) PPVR was the main mechanism of LASM; (3) the cumulative rate of major adverse cardiac events did not differ between the PPVR and the non-PPVR group during the 5-year follow-up period (although ST [late or very late] occurred more frequently in the PPVR group); and (4) both PPVR and LASM were identified as important risk factors of ST along with early ( $<1$-year) discontinuation of dual antiplatelet therapy and longer stent length. To our knowledge, this is the first randomized control study to demonstrate different vascular response in terms of PPVR and LASM between SES and PES implantation and the impact of PPVR and LASM on long-term (5-year) clinical outcomes.

A recent meta-analysis reported that the risk of LASM in patients treated with DES was 2.5-4.0-fold higher compared with those treated with BMS. ${ }^{17}$ In particular, in patients with acute myocardial infarction, the incidence of LASM has been reported to be up to $30.8 \% .^{6}$ In general, 2 mechanisms are thought to contribute to the development of LASM: decreased plaque volume behind the stent due to clot lysis or plaque regression, and positive remodeling of the vessel wall. ${ }^{18,19}$ In the present study which excluded patients with acute myocardial infarction or target lesions with visible thrombus, PPVR appeared to be the main mechanism of LASM. Mechanisms related to PPVR after implantation of DES are still not fully understood. An autopsy study previously suggested that PPVR after SES and PES implantation might be the consequence of chronic inflammation and delayed healing of the arterial wall adjacent to the stent struts. ${ }^{20}$ Previous studies reported LASM incidences of $4-25 \%$ in SES-treated lesions and 2-30.8\% in PES-treated lesions., ${ }^{4,621-24}$ So far, the incidence of LASM has been considered to be similar between SES and PES, but there has been no direct comparison between the 2 first-generation DES types in terms of the incidence of LASM..$^{25,26}$ In a human autopsy study, Nakazawa et al found significantly different histological characteristics in the stented coronary segments depending on the implanted DES type. ${ }^{20}$ Whereas greater inflammation with presence of eosinophils, lymphocytes, and giant cells was noted in SES-treated lesions, ${ }^{27}$ PES-treated lesions were found to have excessive para-strut fibrin accumulation, but less inflammatory reactions. In most SES-treated lesions with severe inflammatory signs, there was PPVR with stent malapposition. Interestingly, there were more prominent inflammatory reactions in SES-treated lesions with longer implant duration. Similar findings were also observed by Cook et al, who performed IVUS and analyzed the histopathology of thrombus aspirates from patients presenting with very late ST after DES implantation. ${ }^{28}$ They found that SES-treated lesions contained more eosinophilic infiltrates than PES- or BMStreated lesions, and the amount of eosinophils correlated with the extent of stent malapposition. ${ }^{28}$ Despite the significantly higher incidence of PPVR and LASM in the SES group, the present study did not find any significant difference in the in- cidence of major adverse cardiac events or ST between SES and PES. This may be due to the relatively small number of patients in the present study. In addition, other lesion-, patient-, and procedure-specific factors may have diluted the impact of LASM because the pathogenic mechanisms of ST are regarded to be multifactorial. In the present study, the frequency of postimplantation dilation and optimal stent expansion was relatively high because of the study design., ${ }^{910}$ Whether increased vascular injury due to post-implantation dilation also contributed to higher incidence of PPVR and LASM in the present study is unclear. It appears, however, to be more likely that achievement of optimal stent expansion does not prevent development of very late ST. Previous clinical studies as well as the present study found LASM to be an important risk factor of late or very late ST. ${ }^{17,29-31}$ According to a meta-analysis, the risk of late or very late ST is increased to 6.5-fold if LASM is noted at follow-up within 12 months. ${ }^{17}$ This is comparable with an HR of 8.01 for late or very late ST in the present patients with LASM. The process by which stent malapposition leads to ST is not fully understood. Delayed re-endothelialization, impaired vasomotion, and chronic inflammation are considered to contribute to the development of ST. In addition, stent malapposition may serve as a local nidus for thrombus formation. ${ }^{19}$ Recently, Kang et al reported that development of stent malapposition was not limited to the first 6 months after implantation, and a considerable number of lesions developed malapposition between 6 months and 2 years. ${ }^{5}$ Based on this finding, PPVR and development of LASM after DES implantation appear to be a chronic process stretching beyond 6-12 months. Therefore, patients with PPVR may still have the potential to develop LASM later on, although LASM was not identified at 9-month follow-up. The present data show steadily increasing cumulative risk of ST in the patients with PPVR or LASM beyond 1 year (Figure). Currently, no proven effective treatment exists for the prevention of ST once LASM is found at follow-up IVUS. Therefore, effective antiplatelet therapy and use of effective, but safer DESs causing less PPVR and LASM seem to be important for the prevention of ST.

Several limitations of this study need to be addressed. First, the number of subjects was relatively small and only twothirds of the patients completed post-intervention and 9-month follow-up IVUS, and clinical 5-year follow-up. Therefore, the present study may have been underpowered to detect differences in clinical outcomes other than ST between the PPVR and non-PPVR groups. Second, the pathomechanisms of the observed ST events were not clear. Therefore, we could not prove whether LASM directly contributed to ST in the present study. Third, because PPVR and LASM occur as a chronic dynamic process, there may have been patients who did not have LASM at 9 months but who may have developed LASM later. Furthermore, we also cannot exclude the possibility that LASM found at IVUS follow-up may resolve at a later stage.

In conclusion, PPVR and LASM after implantation of DES are important independent risk factors of late and very late ST. Therefore, patients with PPVR or LASM at follow-up may need effective dual antiplatelet therapy beyond 1 year. Furthermore, safer DES with less tendency toward PPVR and LASM may be required to prevent later adverse events after stent implantation.

\section{Disclosures}

This study was partly supported by a study grant from Boston Scientific (Natick, Massachusetts) in the form of material supplies and by a grant from the Korea Healthcare Technology R\&D Project, Ministry for Health, Welfare and Family Affairs, Republic of Korea (No. A085012 and A102064); a 
grant from the Korea Health 21 R\&D Project, Ministry of Health and Welfare, Republic of Korea (No. A085136); and the Cardiovascular Research Center, Seoul, Korea

\section{References}

1. Mauri L, Silbaugh TS, Garg P, Wolf RE, Zelevinsky K, Lovett A, et al. Drug-eluting or bare-metal stents for acute myocardial infarction. N Engl J Med 2008; 359: 1330-1342.

2. Dibra A, Kastrati A, Alfonso F, Seyfarth M, Perez-Vizcayno MJ, Mehilli J, et al. Effectiveness of drug-eluting stents in patients with bare-metal in-stent restenosis: Meta-analysis of randomized trials. $J$ Am Coll Cardiol 2007; 49: 616-623.

3. Morice MC, Serruys PW, Sousa JE, Fajadet J, Ban Hayashi E, Perin $\mathrm{M}$, et al. A randomized comparison of a sirolimus-eluting stent with a standard stent for coronary revascularization. N Engl J Med 2002; 346: $1773-1780$.

4. Hong MK. Late stent malapposition after drug-eluting stent implantation: An intravascular ultrasound analysis with long-term follow-up. Circulation 2006; 113: 414-419.

5. Kang SJ, Mintz GS, Park DW, Lee SW, Kim YH, Lee CW, et al. Late and very late drug-eluting stent malapposition: Serial 2-year quantitative IVUS analysis. Circ Cardiovasc Interv 2010; 3: 335-340.

6. Guo N, Maehara A, Mintz GS, He Y, Xu K, Wu X, et al. Incidence, mechanisms, predictors, and clinical impact of acute and late stent malapposition after primary intervention in patients with acute myocardial infarction: An intravascular ultrasound substudy of the Harmonizing Outcomes with Revascularization and Stents in Acute Myocardial Infarction (HORIZONS-AMI) trial. Circulation 2010; 122: $1077-1084$.

7. Vanderhoeven B, Liem S, Dijkstra J, Bergheanu S, Putter H, Antoni $\mathrm{M}$, et al. Stent malapposition after sirolimus-eluting and bare-metal stent implantation in patients with ST-segment elevation myocardial infarction: Acute and 9-month intravascular ultrasound results of the MISSION! Intervention Study. JACC Cardiovasc Interv 2008; 1: $192-201$.

8. van der Hoeven BL, Liem SS, Jukema JW, Suraphakdee N, Putter H, Dijkstra J, et al. Sirolimus-eluting stents versus bare-metal stents in patients with ST-segment elevation myocardial infarction: 9-month angiographic and intravascular ultrasound results and 12-month clinical outcome results from the MISSION! Intervention Study. $J$ Am Coll Cardiol 2008; 51: 618-626.

9. Kim JS, Moon JY, Ko YG, Choi D, Jang Y, Kang WC, et al. Intravascular ultrasound evaluation of optimal drug-eluting stent expansion after poststent balloon dilation using a noncompliant balloon versus a semicompliant balloon (from the Poststent Optimal Stent Expansion Trial [POET]). Am J Cardiol 2008; 102: 304-310.

10. Park SM, Kim JS, Ko YG, Choi D, Hong MK, Jang Y, et al. Angiographic and intravascular ultrasound follow up of paclitaxel- and sirolimus-eluting stent after poststent high-pressure balloon dilation: From the Poststent Optimal Stent Expansion Trial. Catheter Cardiovasc Interv 2011; 77: 15-21.

11. de Jaegere P, Mudra H, Figulla H, Almagor Y, Doucet S, Penn I, et al. Intravascular ultrasound-guided optimized stent deployment: Immediate and 6 months clinical and angiographic results from the Multicenter Ultrasound Stenting in Coronaries Study (MUSIC Study). Eur Heart J 1998; 19: 1214-1223.

12. Mintz GS, Nissen SE, Anderson WD, Bailey SR, Erbel R, Fitzgerald PJ, et al. American College of Cardiology Clinical Expert Consensus Document on Standards for Acquisition, Measurement and Reporting of Intravascular Ultrasound Studies (IVUS): A report of the American College of Cardiology Task Force on Clinical Expert Consensus Documents. J Am Coll Cardiol 2001; 37: 1478-1492.

13. Degertekin M, Serruys PW, Tanabe K, Lee CH, Sousa JE, Colombo A, et al. Long-term follow-up of incomplete stent apposition in patients who received sirolimus-eluting stent for de novo coronary lesions: An intravascular ultrasound analysis. Circulation 2003; 108: 2747-2750.
14. Mauri L, Hsieh WH, Massaro JM, Ho KK, D’Agostino R, Cutlip DE. Stent thrombosis in randomized clinical trials of drug-eluting stents. N Engl J Med 2007; 356: 1020-1029.

15. Tanabe K, Serruys PW, Degertekin M, Grube E, Guagliumi G, Urbaszek W, et al. Incomplete stent apposition after implantation of paclitaxel-eluting stents or bare metal stents: Insights from the randomized TAXUS II trial. Circulation 2005; 111: 900-905.

16. Cutlip DE, Windecker S, Mehran R, Boam A, Cohen DJ, van Es GA, et al. Clinical end points in coronary stent trials: A case for standardized definitions. Circulation 2007; 115: 2344-2351.

17. Hassan AKM, Bergheanu SC, Stijnen T, van der Hoeven BL, Snoep JD, Plevier JWM, et al. Late stent malapposition risk is higher after drug-eluting stent compared with bare-metal stent implantation and associates with late stent thrombosis. Eur Heart J 2010; 31: $1172-$ 1180.

18. Ko YG, Son JW, Park SM, Kim JS, Choi D, Hong MK, et al. Effect of vessel size on lipid content of coronary plaques assessed by integrated backscatter intravascular ultrasound. Circ J 2010; 74: 754759.

19. Cook S, Wenaweser P, Togni M, Billinger M, Morger C, Seiler C, et al. Incomplete stent apposition and very late stent thrombosis after drug-eluting stent implantation. Circulation 2007; 115: 2426-2434.

20. Nakazawa G, Finn AV, Vorpahl M, Ladich ER, Kolodgie FD, Virmani R. Coronary responses and differential mechanisms of late stent thrombosis attributed to first-generation sirolimus- and paclitaxel-eluting stents. J Am Coll Cardiol 2011; 57: 390-398.

21. Nakazawa G, Finn A, John M, Kolodgie F, Virmani R. The significance of preclinical evaluation of sirolimus-, paclitaxel-, and zotarolimus-eluting stents. Am J Cardiol 2007; 100: S36-S44.

22. Miyazawa A, Ako J, Hongo Y, Hur SH, Tsujino I, Courtney BK, et al. Comparison of vascular response to zotarolimus-eluting stent versus sirolimus-eluting stent: Intravascular ultrasound results from ENDEAVOR III. Am Heart J 2008; 155: 108-113.

23. Sakurai R, Bonneau HN, Honda Y, Fitzgerald PJ. Intravascular ultrasound findings in ENDEAVOR II and ENDEAVOR III. Am J Cardiol 2007; 100: 71M-76M.

24. Rathore S, Terashima M, Habara M, Kinoshita Y, Nasu K, Katoh O, et al. Incomplete stent apposition after coronary stent implantation: Myth or reality? J Interv Cardiol 2009; 22: 341-349.

25. Kim JS, Kim TH, Fan C, Lee JM, Kim W, Ko YG, et al. Comparison of neointimal coverage of sirolimus-eluting stents and paclitaxel-eluting stents using optical coherence tomography at 9 months after implantation. Circ J 2010; 74: 320-326.

26. Miyoshi N, Shite J, Shinke T, Otake H, Tanino Y, Ogasawara D, et al. Comparison by optical coherence tomography of paclitaxel-eluting stents with sirolimus-eluting stents implanted in one coronary artery in one procedure: 6-month follow-up. Circ J 2010; 74: 903-908.

27. Virmani R, Guagliumi G, Farb A, Musumeci G, Grieco N, Motta T, et al. Localized hypersensitivity and late coronary thrombosis secondary to a sirolimus-eluting stent: Should we be cautious? Circulation 2004; 109: 701-705.

28. Cook S, Ladich E, Nakazawa G, Eshtehardi P, Neidhart M, Vogel R, et al. Correlation of intravascular ultrasound findings with histopathological analysis of thrombus aspirates in patients with very late drugeluting stent thrombosis. Circulation 2009; 120: 391-399.

29. Siqueira DA, Abizaid AA, Costa Jde R, Feres F, Mattos LA, Staico $\mathrm{R}$, et al. Late incomplete apposition after drug-eluting stent implantation: Incidence and potential for adverse clinical outcomes. Eur Heart $J$ 2007; 28: 1304-1309.

30. Hoffmann R, Morice MC, Moses JW, Fitzgerald PJ, Mauri L, Breithardt $\mathrm{G}$, et al. Impact of late incomplete stent apposition after sirolimus-eluting stent implantation on 4-year clinical events: Intravascular ultrasound analysis from the multicentre, randomised, RAVEL, E-SIRIUS and SIRIUS trials. Heart 2008; 94: 322-328.

31. Hong MK, Mintz GS, Lee CW, Park DW, Lee SW, Kim YH, et al. Impact of late drug-eluting stent malapposition on 3-year clinical events. J Am Coll Cardiol 2007; 50: 1515-1516. 